\title{
The new wild: The uncomfortable truth
}

\section{BOOK TITLE:}

The new wild: Why invasive species will be nature's salvation

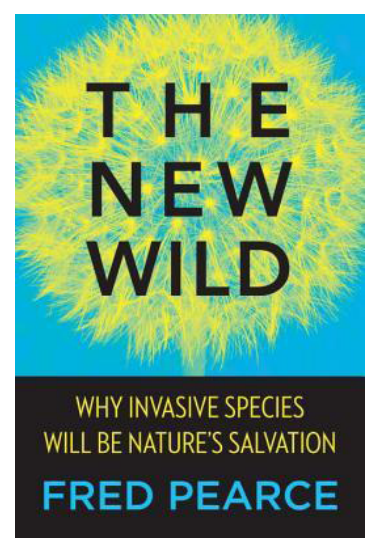

AUTHOR:

Fred Pearce

ISBN:

9780807033685 (hardcover)

\section{PUBLISHER:}

Beacon Press, Boston; USD26.95

\section{PUBLISHED: \\ 2015}

\section{REVIEWER:}

Roy A. Lubke

\section{EMAIL:}

r.lubke@ru.ac.za

\section{AFFILIATION:}

'Department of Botany, Rhodes University, Grahamstown, South Africa

\section{POSTAL ADDRESS:}

Department of Botany, Rhodes University, Grahamstown 6140, South Africa

\section{HOW TO CITE:}

Lubke RA. The new wild: The uncomfortable truth. S Afr J Sci. 2016;112(7/8), Art. \#a0163, 2 pages. http://dx.doi. org/10.17159/sajs.2016/a0163

(C) 2016. The Author(s). Published under a Creative Commons Attribution Licence.
Fred Pearce, an environmental journalist from London, has produced a book that will set the proverbial cat amongst the pigeons of restoration ecology. For some decades, ecologists have been set on eradicating alien invasive species and restoring pristine environments. In this book, Pearce exposes their efforts as fruitless, because there is no such thing as a pristine environment on earth. All environments have been disturbed by humans. Pearce is also of the opinion that many of these so-called harmful introduced species may in fact be beneficial in cleaning up degraded or polluted environments.

Pearce has extensive experience in scientific reporting - he has written five books on similar topics. These topics include the demise of earth's water resources, the human population crisis and climate change. Now he attempts to provide an optimistic outcome to human 'interference' in nature, by accepting that invasive species are part of 'the new wild'. This view directly contrasts that of Paddy Woodworth ${ }^{1}$ who, in an analysis of restoration projects around the world, champions the work of restoration ecologists by describing their successful projects. Pearce quotes many examples in which alien species have simply fitted into the new habitats, often benefitting the changed ecosystems. Is there a middle road where both approaches are compatible? A more detailed analysis of The New Wild might answer this question.

In Part 1 of the book, titled 'Alien empires', Pearce analyses several alien invasions and the 'myths' behind these invasions, many of which are commonly reported in the popular press. Pearce contends that alien species are, with human help, moving into disturbed places where they are often 'helping nature's recovery'. The first chapter (On Green Mountain) is about islands, where some of the greatest damage to ecosystems has occurred. Pearce states that the 'malign invaders were simply taking advantage of ecosystems that had already been wrecked by humans' and the invaders 'were often doing jobs that natives could not accomplish' as they were regenerates of the disturbed environment. For example, on Ascension Island in the South Atlantic, 90\% of the biota now comprises alien sources, and it is unlikely that restoration is possible. However, the loss of rare and endangered species, such as birds from other islands that are sparsely populated, is hardly comparable, and there is an inconsistency in Pearce's theory. Should we simply accept that on most islands, 'alien species add to local diversity and enrich species-poor ecosystems' - even when rare species are being decimated on remote islands? Ecologists working to save colonies of seabirds that have been ransacked by invasive rats or cats are unlikely to accept this view.

Chapter 2 (New Worlds) is on the accidental introduction of weeds, pests and diseases. Pearce attempts to lessen the blow caused by these 'villains', explaining that their presence is the result of people's pollution or other disturbances of habitats, and contending that such species fit in with the 'new ecosystem'. Ecologists and conservationists who witness disturbances to aquatic systems by invading water weeds or thickets of introduced alien woody plants displacing grasslands or fynbos, would hardly find this idea acceptable. Pearce also examines the invasion of marine habitats by alien species (Chapter 3) and the alien invaders of America (Chapter 4) and Britain (Chapter 5). Top of the British hate list for weeds is Japanese knotweed. Pearce gives an almost comical account of the ridiculousness of being overly obsessed with alien invasive species. He analyses the costs of clearing the weed, citing claims of a '\$250-million-a-year problem - or a pint of beer for every person in the land', which is disputed by some ecologists working on the weed.

In Part 2 of the book, titled 'Myths and demons', Pearce refers to 'our misplaced notions about how aliens affect the real world and how we do conservation'. This section of the book is likely to rile conservationists, restoration ecologists and biological control scientists, especially in South Africa.

Chapter 6 (Ecological Cleansing) reports on the mega-project of Working for Water in eradicating alien woody species that are annihilating natural ecosystems and sapping South African water supplies. Pearce rather frivolously considers this a 'rarely successful' process of ecological cleansing. His opinion is based largely on the high cost of the operation for very little return of land restored, and the fact that alien seeds remain in the soil - meaning alien plants are likely to return. He argues that the tree species being eradicated in South Africa are encouraged for use in arid northern areas in Africa, to increase 'the water-holding capacity of soils and generate income for farmers'. There is no mention of the aesthetics of an environment of alien thicket species compared with restored mountain fynbos. Pearce also does not mention the loss of grazing land to alien invasions. He describes many other studies of eradication, and the chapter ends thus: 'Conservationists, it seems, are dedicated to protecting the weak and vulnerable, the endangered and the abused. Nature generally promotes the strong and the wily, the resilient and versatile.' The reader is left to wonder whether this is an argument to allow invasive species to take over.

Chapter 7 (Myths of the Aliens) charts the development of 'invasion biology'. Pearce begins by discussing the work of Elton, who wrote The Ecology of Invasions by Animals and Plants (1958) and promoted the study of 'ecological explosions' of alien biota. Pearce cites many alleged facts and figures about alien species and the contradictions made by ecologists. He concludes that despite all the inconsistencies and 'myths' about invasive species, there is still a strong call for academics to support action against invasive species.

Most of Chapter 8 (Myths of the Pristine) describes so-called pristine environments such as tropical forests, nearly all of which are in fact disturbed or influenced by people. There is overkill in Pearce's argument here. Although many ecologists agree that the pristine environment concept is overstated, numerous sites do still exist on the globe that have been little affected by humans.

Chapter 9 (Nativism in the Garden of Eden) explores Clements' idea of collective associations of plants, and contrasts it with Gleason's concept of individualistic action of species. Gleason's concept fits Pearce's view that alien species introduced into new habitats act individualistically and can fit in with the ecosystem. The ecological 
concept of associations is derided as it does not suit Pearce's ideas on the new wild. Pearce cites succession on the newly formed volcanic island of Surtsey, near Iceland, as an example of the haphazard formation of a new ecosystem - such as in his concept of the new wild. Many ecologists will question the shallowness of his arguments to advance his concepts.

Having described the myths, in the final part of his book (The New Wild), Pearce attempts to offer some solutions. He believes we need to change our ideas on conservation and 'lose our dread of the alien and the novel'. Alien species and novel ecosystems will be the heart of the new wild.

In Chapter 10 (Novel Ecosystems), Pearce never really defines what restoration ecologists mean by 'novel ecosystems'. Restoration ecologists have discovered that in attempting to recreate the original system, an ecological threshold is often encountered and is very difficult to overcome. This 'new' unoriginal state is the so-called novel ecosystem. By contrast, Pearce's concept of a novel ecosystem is one in which humans have introduced alien species, often in a disturbed environment, and 'the system itself does not depend on humans to keep it going'. He cites examples such as Puerto Rico, where disturbed secondary forests are invaded by and contain many introduced species. He quotes Lugo et al. ${ }^{2}$ as calling this the 'new wild' where transformed sites are 'beautifully functioning new forests, with greater biodiversity than the old forests'.

In Chapter 11 Pearce promotes railway sidings, landfill sites, graveyards, market gardens and brownfield sites as unique habitats, where many rare and endangered plant species find refuge and protection. Such sites are part of the new wild. He also describes how many animals find cities safer than the countryside. The ugliness of these environments and how they would mesh with graceful parks and gardens is not considered.

In the concluding chapter (Call of the New Wild), Pearce explores the effects of climate change and hybridisation of species, and how these trends will contribute to changes in community assemblages in creating the new wild. He feels that in this century, biologists should not fight a losing battle to protect 'pristine nature' but should rather encourage the rebirth of nature, and accept invasive alien species.

Is there a middle road between alien eradication on the one hand, and, on the other, restoration of environments and acceptance of the new wild, such that both approaches are compatible? The answer is ' $N o$ '. If biologists were to accept these concepts, they would have to give up all they have attempted to achieve in conserving endangered species and restoring 'pristine' environments - often regarded as 'wilderness' areas. Pearce disregards aesthetics and the beauty of the natural environment, which ecotourists travel to view every day. His arguments also make no mention of how to use the new wild. Environmentalists are closely involved in trying to maintain or restore desirable sites for appropriate use by people. Land use is not considered in Pearce's book, and I also see no tranquillity as a 'sense of place' in the new wild.

Despite the lack of depth of research and the shortcomings mentioned above, there is a need for a book like this to be widely read by the scientific community. Firstly, Pearce has noted that he is 'far from alone' in his concern 'that we have bought into some dangerous mythology about how nature works'. We need to re-examine the literature in which there is opposition to the eradication of invasive aliens and ecosystem restoration. Perhaps we have overlooked, as Pearce claims, figures regarding the danger of aliens and costs of their eradication. Secondly, experts must interrogate Pearce's arguments and pose counterarguments to their students and in their publications. Thirdly, experts working on projects of alien eradication or ecosystem restoration should read this book carefully to enforce their requests for funding, because of the question Pearce raises about the possible waste of such funding. Fourthly, environmentalists, ecologists and conservationists involved in planning and environmental impact assessments might find his arguments (such as 'there is no such thing as a pristine ecosystem') used by developers who wish to push their projects through the environmental impact assessment or planning phases. On such grounds, scientists and the concerned public should retain the useful ideas in Pearce's book and reject the rest.

Finally, what is the uncomfortable truth in this book? However scientists feel about its concepts, what Pearce proposes as the 'new wild' will certainly occur sometime in the future. On Ascension Island, it is happening already. Ecologists cannot indefinitely eradicate all aliens from 'pristine' or even slightly disturbed environments. We will have to limit our resources to some areas, while allowing new systems - the new wild - to develop in others. Moreover, humans might not be present on this planet forever. Then, as Pearce claims in his final paragraph, 'nature never goes back; it always moves on'. The vagabonds or aliens will be the pioneers and colonists in this constant renewal, and the new wild will become a reality across the planet.

\section{References}

1. Woodworth P. Our once and future planet: Restoring the world in the climate change century. Chicago, IL: University of Chicago Press; 2013. p.515.

2. Lugo AE, Carlo TA, Wunderle JM. Natural mixing of species: Novel plantanimal communities on Caribbean Islands. Anim Conserv. 2012;15(3):233241. http://dx.doi.org/10.1111/j.1469-1795.2012.00523.x 